\title{
Close-to-nature management positively improves the spatial structure of Masson pine forest stands
}

\author{
Xianfeng Fang ${ }^{1}$, Wei Tan ${ }^{1}$, Xiaoye Gao ${ }^{2}$, and Zongzheng Chai ${ }^{1}$ \\ ${ }^{1}$ College of Forestry, Guizhou University, Guiyang 550025, Guizhou, PR China \\ ${ }^{2}$ College of Eco-Environmental Engineering, Guizhou Minzu University, Guiyang 550025, Guizhou, PR China
}

Correspondence: Zongzheng Chai (chaizz@ 126.com)

Received: 25 May 2020 - Revised: 31 October 2020 - Accepted: 10 November 2020 - Published: 15 February 2021

\begin{abstract}
Close-to-nature management (CTNM) has been proposed as a promising forestry management approach to improve the structure and quality of forests, which integrates wood production and ecological service functions. Research on the effect of CTNM on the univariate and bivariate distribution of the spatial structure of forest stands provides a scientific basis for the evaluation of CTNM implemented in forestry. Here, we analyzed and compared the spatial-structure characteristics of Masson pine (Pinus massoniana) plantations (young, middle-age, and near-mature stages) under CTNM 8 years after selective cutting and unmanaged control. We used univariate and bivariate distribution of three spatial-structure parameters: mingling $(M)$, dominance $(U)$, and uniform-angle index $(W)$. Results showed that the effect of CTNM on spatial structure was more remarkable in middle-aged and near-mature Masson pine forests compared with the young forest. CTNM significantly improved mingling degree and promoted the horizontal distribution, thereby changing from a cluster to a random distribution. Moreover, CTNM improved the proportion of trees with a high mixing degree and random distribution and the proportion of trees having a micro-structure of random distribution with a high degree of mixture and dominance with a high degree of mixture in middle-aged and near-mature Masson pine forest. Overall, the implementation of CTNM 8 years ago showed a positive effect on the improvement of the spatial structure of Masson pine forest, but the present spatial structure is suboptimal. Further implementation of CTNM to adjust the mingling and uniform-angle index is necessary, and CTNM according to this method of frequency distribution of stand structure parameters can improve the success of forest management.
\end{abstract}

\section{Introduction}

Close-to-nature management (CTNM) is a promising forestry management approach, which simultaneously integrates wood production and ecological service functions of a forest at a relatively small spatial scale, such as stand level, by developing a structure similar to that of an original forest (O'Hara, 2016; Wang et al., 2018). In this method, trees of different ages and sizes are distributed in the same stand, new trees are established through natural recruitment, and lumber harvest selectively occurs throughout the forest stand (Li et al., 2014a). Since forests should be managed following their natural processes, the stand development stages are key to CTNM, for example arranging corresponding silvicultural and cutting operations along multiple management cycles (Wang et al., 2018). Ultimately, the effect of CTNM on a forest can be partly reflected in the spatial-structure characteristics of stands.

The species composition, tree size, and distribution pattern are important structural attributes considered in forest management. These attributes directly indicate interand intraspecific competition, seedling recruitment, and tree growth, and the use of environmental resources by animals and plants indirectly affects these attributes ( $\mathrm{Li}$ et al., 2014b). A group of neighborhood-based structural parameters (based on the relationship between a reference tree and its four nearest neighbors) consisting of three indices - mingling $(M)$, dominance $(U)$, and uniform-angle index $(W)$ - can reflect these structural attributes (Chai et al., 2017; Hui et al., 2006). Previous studies mainly used univariate distribution or the average value of these parameters to evaluate the spatial- 
structural attributes (mixture, predominance, and distribution pattern of tree species) of a forest (Ghalandarayeshi et al., 2017; Li et al., 2017), and they have demonstrated that these three spatial-structure parameters have a strong operability for guiding forestry (Hui et al., 2019; Zhang et al., $2018 b$ ). To provide more important and specific information, and to better understand the fine-scale spatial structure of tree populations and stand structure, the bivariate distribution of structural characteristics was proposed (Li et al., 2012). It has been used to analyze the fine spatial structure of broadleaved forest of Korean pine in northeast China and has been successfully validated several times (Ghalandarayeshi et al., 2017; Li et al., 2014a; Wan et al., 2019).

Masson pine (Pinus massoniana) from plantations is a pioneer coniferous tree species extensively used for afforestation, which is widely distributed in central and southern China (Guan and Wen, 2011; Maleki et al., 2018). It provides a great amount of lumber, making it economically important (Du et al., 2018). Since short-term production of Masson pine plantations has been prioritized for the pursuit of economic interests, the health and quality of the species have been ignored (Chen et al., 2015). For a long time, monoculture has covered a large area, and unreasonable methods of harvest have caused many ecological problems, such as low productivity, soil degradation, pests, diseases, and decreased biodiversity (Zhang et al., 2019). Finding a solution to these problems and implementing sustainable management of Masson pine plantations are the current focus of forest research in these regions. Many international and domestic research and management practices have shown that CTNM is effective at improving the quality and ecological benefits of a plantation (O’Hara, 2016; Sackov et al., 2017; Wu et al., 2013).

Research on the effect of CTNM on Masson pine from plantations and the stage of development where the best effect of CTNM appears lacks the support of relevant literature. Therefore, we analyzed and compared the spatialstructure characteristics of Masson pine plantations (young, middle-aged, and near-mature stages) under CTNM and unmanaged control 8 years after selective cutting. The goals of this study are (1) to compare the spatial-structure characteristics of managed and unmanaged Masson pine and (2) to analyze the spatial-structure characteristics of Masson pine at different development stages. Our results will contribute to the sustainable development of Masson pine from plantations in central Guizhou Province of China.

\section{Materials and methods}

\subsection{Study area}

The study area is located in Kaiyang and Xifeng counties of Guizhou Province in China, with geographical coordinates of $26^{\circ} 48^{\prime}-27^{\circ} 22^{\prime} \mathrm{N}, 106^{\circ} 45^{\prime}-107^{\circ} 17^{\prime} \mathrm{E}$ and $26^{\circ} 57^{\prime}-27^{\circ} 19^{\prime} \mathrm{N}$, $106^{\circ} 27^{\prime}-106^{\circ} 53^{\prime} \mathrm{E}$, respectively. These counties have similar climatic conditions, experiencing a subtropical humid and mild climate with a mean annual temperature of $15.3^{\circ} \mathrm{C}$. The mean annual rainfall is $1200 \mathrm{~mm}$, concentrated from July to September. The original vegetation has been destroyed, leaving Pinus massoniana, Cunninghamia lanceolata, and evergreen broad-leaved forest as the main forest types.

\subsection{Study site and data collection}

In the spring of 2009, the CTNM began with the implementation of the Sino-German cooperation project. Different CTNM measures were adopted for different development stages of Masson pine plantations, which contained tending, thinning, selective logging, and natural restoration (Table 1). No forestry operations were conducted during the different development stages, which were referred to as the control.

Nineteen sample blocks were set in the major distribution areas of Pinus massoniana CTNM by considering different development stages. Since most Masson pine from plantations was at middle-to-mature development stages, three, seven, and nine blocks were selected for the young, middleaged, and near-mature forest, respectively. Each block contained a CTNM sample plot (managed treatment) and an unmanaged sample plot (control treatment); they showed similar site conditions at different stages of Masson pine plantations and were randomly established and surveyed at the research area (Fig. 1). The diameter at breast height (DBH), tree height, tree species, and crown width were recorded, and the spatial-structure parameters were calculated using these data to assess the influence of CTNM on the spatial structure of forest stands.

\subsection{Data analysis}

\section{Importance value (IV)}

The importance value (IV) of species is defined as the average relative density (RD), relative frequency (RF), and relative dominance $(\mathrm{Rd})$ and was calculated using the following equations (Chai et al., 2017):

density $(D)=\frac{\text { number of individuals of a species }}{\text { area of all sample units }}$,

telative abundance $(\mathrm{RD})=$

$$
\frac{\text { number of individuals of a species }}{\text { density for all species }} \times 100 \%,
$$

frequency $(F)=$

$\frac{\text { number of quadrats containing a certain species }}{\text { total number of quadrats }}$,

relative frequency $(\mathrm{RF})=$

$\frac{\text { frequency of a certain species }}{\text { total number of species }} \times 100 \%$,

dominance $(d)=\frac{\text { basal area of a species }}{\text { area of all sample units }}$ 
Table 1. Close-to-nature management measures at different development stages of Masson pine plantations.

\begin{tabular}{llll}
\hline $\begin{array}{l}\text { Development } \\
\text { stages }\end{array}$ & Stand DBH & CTNM measures & $\begin{array}{l}\text { Target density } \\
(\text { trees hm }\end{array}$ \\
\hline $\begin{array}{l}\text { Young forest } \\
\text { Middle-aged forest }\end{array}$ & $5 \mathrm{~cm} \leq 5 \mathrm{DBH}<15 \mathrm{~cm}$ & $\begin{array}{l}\text { Regulate stand density and remove overlord wood and bent trees } \\
\text { Combination of target tree and thinning density control }\end{array}$ & $\begin{array}{l}\text { About } 2500 \\
1200-1700\end{array}$ \\
Near-mature & $15 \mathrm{~cm} \leq \mathrm{DBH}<34 \mathrm{~cm}$ & Combination of target tree and thinning density control & $300-850$ \\
\hline
\end{tabular}

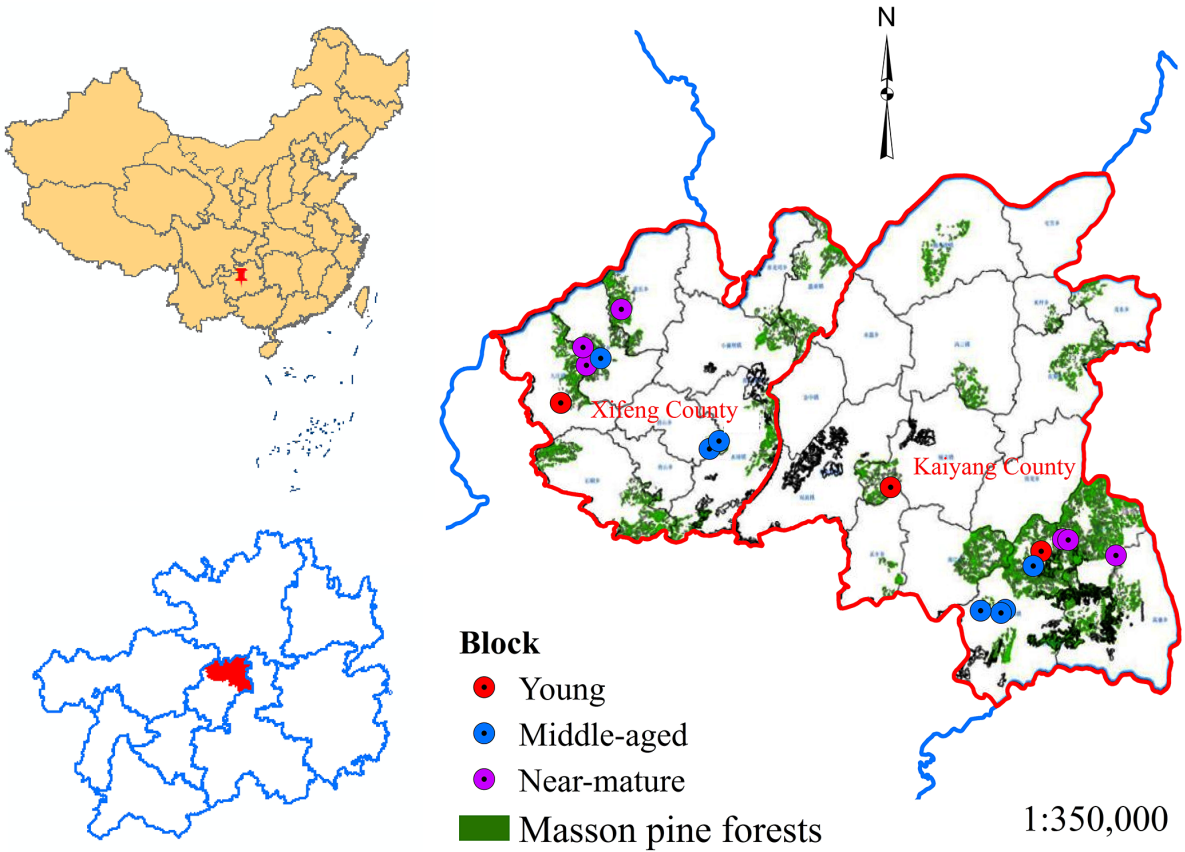

Figure 1. The distribution of the 19 sample blocks (Chai and Tan, 2020).

relative dominance $(\mathrm{Rd})=$ $\frac{\text { dominance of one species }}{\text { domiance of all species }} \times 100 \%$,

$\mathrm{IV}=(\mathrm{RD}+\mathrm{RF}+\mathrm{Rd}) / 3$.

\section{Spatial-structure parameters}

In this study, the neighborhood-based indices (mingling, dominance, and uniform-angle index) were used to show the spatial structure of a forest stand. These indices can show small-scale variations in tree species, tree diameter, and distribution patterns in a small structural unit and have proven useful for the analysis of the spatial structure of forest stands (Ghalandarayeshi et al., 2017; Hui et al., 2019). Mingling describes the spatial segregation of different species in a multispecies forest and is defined as the proportion of the four nearest neighbors of different species from the reference tree $i$ (Gadow and Füldner, 1993). Dominance characterizes the size differentiation (i.e., DBH dominance) between a reference tree and its four nearest neighbors and is defined as the proportion of $\mathrm{n}$ nearest neighbors larger than reference tree $i$ (Aguirre et al., 2003). The uniform-angle index describes the degree of regularity of the four neighbors nearest to reference tree $i$ and is defined as the proportion of the angle $(\alpha)$ that is smaller than the standard angle $\alpha_{0}\left(72^{\circ}\right)$ (Gadow et al., 1998; Hui et al., 2007; Zhao et al., 2014). The bounds $[0.475,0.517]$ defined the average $W$ for the random case. A $W$ value less than 0.475 most likely corresponds to a regular distribution, and values exceeding 0.517 most likely correspond to a cluster distribution (Hui and Gadow, 2002; Hui et al., 2004).

A univariate distribution of these parameters (mingling, dominance, and uniform-angle index) is widely used to analyze the structural attributes of forest communities and populations, and the mean value of these parameters has been demonstrated to properly reflect the overall attributes of an entire species or stand (Hui et al., 1999, 2007). In addition, these parameters can be analyzed as joint distributions of three pairwise variable combinations (bivariate distribution): $M-U, M-W$, and $U-W$. Each joint distribution contains $25(5 \times 5)$ structural combinations that enable the analy- 
sis of stand micro-structure (Chai et al., 2017; Li et al., 2012, 2014a).

Corresponding equations of three neighborhood-based indices are as follows:

1. mingling (Gadow and Füldner, 1993; Hui et al., 2011):

$$
\begin{aligned}
M_{i} & =\frac{1}{n} \sum_{j=1}^{n} v_{i j}, \text { with } v_{i j}= \\
& \left\{\begin{array}{l}
1, \text { species }_{j} \neq \text { species }_{i} \\
0, \text { otherwise }, \text { and } 0 \leq M_{i} \leq 1 ;
\end{array}\right.
\end{aligned}
$$

2. dominance (Aguirre et al., 2003):

$$
\begin{aligned}
& U_{i}=\frac{1}{n} \sum_{j=1}^{n} k_{i j}, \text { with } k_{i j}= \\
& \quad\left\{\begin{array}{l}
0, d_{j}<d_{i} \\
1, \text { otherwise }
\end{array}, \text { and } 0 \leq U_{i} \leq 1 ;\right.
\end{aligned}
$$

3. uniform-angle index (Gadow et al., 1998; Hui et al., 2007):

$$
\begin{aligned}
& W_{i}=\frac{1}{n} \sum_{j=1}^{n} z_{i j} \text { with } z_{i j}= \\
& \left\{\begin{array}{l}
1, \alpha_{j}<\alpha_{0} \\
0, \text { otherwise }
\end{array} \text {, and } 0 \leq W_{i} \leq 1 .\right.
\end{aligned}
$$

The variables in these equations are as follows: $n$ is the number of neighbors, and in this study $n=4 ; d_{i}$ and $d_{j}$ are the $\mathrm{DBH}$ of the reference tree and neighboring tree, respectively; $\alpha_{j}$ is the horizontal angle between the reference tree and four neighboring trees; and a standard angle $\alpha_{0}=72^{\circ}$. All indices have a series of flexible values at five values: 0.00 , $0.25,0.50,0.75$, and 1.00 .

\section{Results}

\subsection{Tree species composition}

The 38 sample plots contained 20 tree species and 2070 trees (DBH $\geq 5 \mathrm{~cm}), 1792$ of which were P. massoniana $(86.57 \%$ of the total). Table 2 shows a list of the abundance and importance values of each species in the managed and control treatments at three stages of development. The species abundance in managed treatments was higher than the control, especially for the managed middle-aged and near-mature stands. Correspondingly, the importance values were lower in managed treatments compared with the control $(80.448$ vs. 88.585 for young stands, 71.821 vs. 82.792 for middleaged stands, and 69.822 vs. 84.068 for near-mature stands) (Table 2).

\subsection{Univariate distribution of spatial-structure parameters}

Average spatial-structure parameters showed that mingling in the managed treatments was significantly higher than mingling in the control, and all mingling values were lower than 0.5 . Only the young stand showed a higher dominance in the managed than in the control treatment. The uniform-angle index in middle-aged and near-mature stands was 0.491 and 0.504 , respectively, which were between $0.475-0.517$, whereas the uniform-angle index in all other stands was higher than 0.517 (Table 3).

The frequency distribution of spatial-structure parameters indicated that trees in the control treatment were concentrated with a low degree of mixture $(M=0.00,0.25)$ regardless of the stage of stands, while the relative frequency of trees with a medium-high degree of mixture increased in the managed middle-aged and near-mature stands. Trees in all stands were evenly distributed at each level of dominance, and no significant differences were observed between the control and managed treatments. Most trees in all stands were located at random $(W=0.50)$, and the relative frequency of trees with clumped distribution $(W=0.75,1.00)$ decreased in managed treatments compared with the control (Fig. 2).

\subsection{Bivariate distribution of the spatial-structure parameters}

\subsubsection{Mingling $(M)-$ dominance $(U)$ distribution}

Most trees in all stands were concentrated with a structural combination of $M=0.00$ and $U=0.00-1.00$, which showed a total frequency in the control and managed treatments of 0.885 and 0.697 in young stands, 0.701 and 0.351 in middle-aged stands, and 0.646 and 0.320 in near-mature stands, respectively. Furthermore, the relative frequency of trees with a high mixture $(M=0.75,1)$ and low dominance $(U=0,0.25)$ was higher in managed treatments compared with the control, which were 0.071 vs. 0.019 in middle-aged stands and 0.105 vs. 0.011 in near-mature stands, respectively (Fig. 3).

\subsubsection{Mingling $(M)$-uniform-angle index $(W)$ distribution}

Regardless of the kind of stand, the $M-W$ bivariate distribution showed that the maximum frequency appears at $M=0$ at each row of the uniform-angle index $(W)$, and the frequency at each column of mingling $(M)$ initially increased and then decreased with the increase of $W$ classes, which reached its maximum at $W=0.5$. Moreover, compared with the control, relative frequency of trees in managed treatments with high mingling $(M=1)$ and a random distribution ( $W=0.5$ ) was improved, showing 0.013 vs. $0.051,0.037$ vs. 0.068 , and 0.039 vs. 0.078 for young, middle-aged, and nearmature stands, respectively (Fig. 4). 

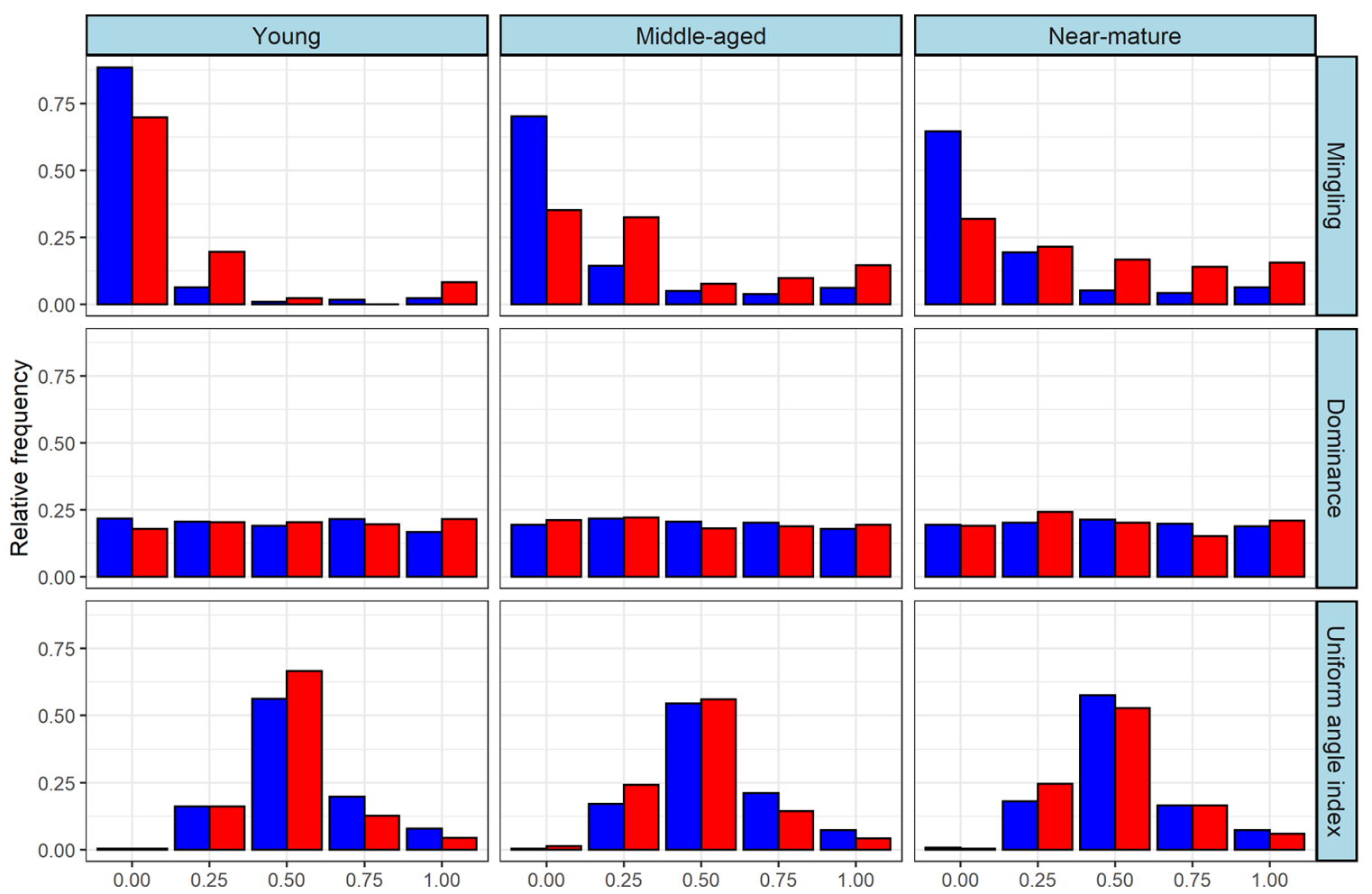

Figure 2. Frequency distribution of the spatial-structure parameters at different tree ages.
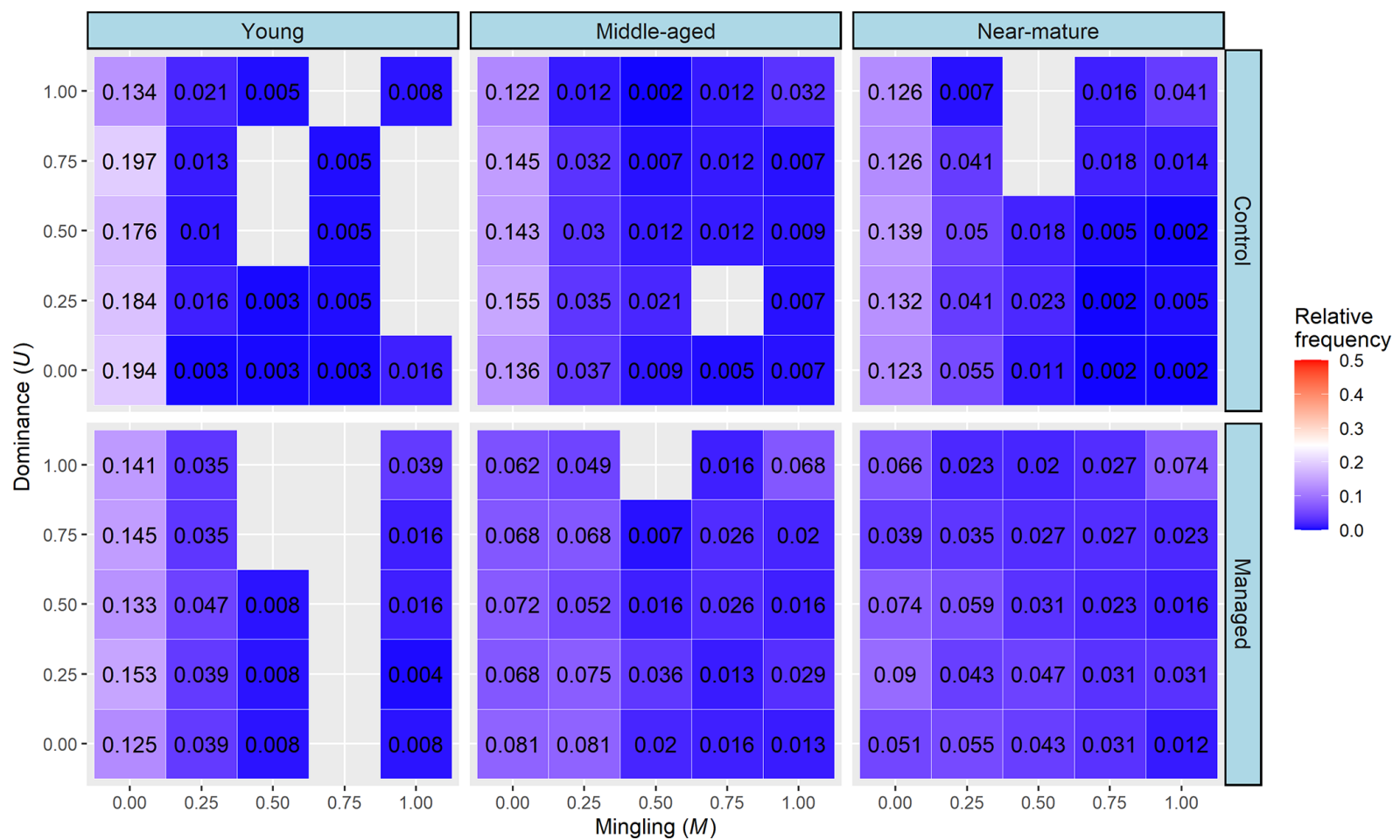

Figure 3. Bivariate distribution of $M$ and $U$ at different tree ages. 
Table 2. Composition and importance value index of tree species under close-to-nature management.

\begin{tabular}{|c|c|c|c|c|c|c|c|}
\hline \multirow{3}{*}{ Species } & \multirow{3}{*}{ Abundance } & \multicolumn{6}{|c|}{ Abundance/importance value } \\
\hline & & \multicolumn{2}{|c|}{ Young } & \multicolumn{2}{|c|}{ Middle-aged } & \multicolumn{2}{|c|}{ Near-mature } \\
\hline & & Control & Managed & Control & Managed & Control & Managed \\
\hline Pinus massoniana Lamb. & 1792 & $365 / 88.585$ & $234 / 80.448$ & $370 / 82.792$ & $243 / 71.821$ & $393 / 84.068$ & $187 / 69.822$ \\
\hline $\begin{array}{l}\text { Cunninghamia lanceolata } \\
\text { (Lamb.) Hook. }\end{array}$ & 77 & $2 / 3.669$ & $7 / 7.913$ & $25 / 5.366$ & $12 / 5.576$ & $20 / 4.991$ & $11 / 6.501$ \\
\hline $\begin{array}{l}\text { Liquidambar formosana } \\
\text { Hance }\end{array}$ & 55 & - & $2 / 3.816$ & $3 / 3.624$ & $15 / 11.874$ & $14 / 8.200$ & $21 / 12.038$ \\
\hline Quercus fabri Hance & 21 & $4 / 3.443$ & $2 / 1.975$ & $1 / 0.896$ & $3 / 1.371$ & - & $11 / 4.626$ \\
\hline $\begin{array}{l}\text { Quercus acutissima } \\
\text { Carruth. }\end{array}$ & 16 & - & $1 / 1.172$ & $7 / 0.976$ & $4 / 0.755$ & - & $4 / 2.058$ \\
\hline $\begin{array}{l}\text { Cryptomeria fortunei } \\
\text { Hooibrenk ex Otto et Dietr }\end{array}$ & 15 & $5 / 1.536$ & $7 / 2.974$ & - & $3 / 0.650$ & - & - \\
\hline Fagus longipetiolata & 15 & - & - & $5 / 2.434$ & $9 / 3.149$ & - & $1 / 0.536$ \\
\hline $\begin{array}{l}\text { Pterocarya stenoptera } \\
\text { C. DC }\end{array}$ & 13 & $5 / 2.766$ & $2 / 1.702$ & - & $2 / 0.525$ & $4 / 0.756$ & - \\
\hline $\begin{array}{l}\text { Cinnamomum camphora } \\
\text { (L.) Presl. }\end{array}$ & 12 & - & - & $12 / 1.292$ & - & - & - \\
\hline Phoebe zhennan S. Lee & 10 & - & - & - & $1 / 0.498$ & $1 / 0.307$ & $8 / 2.119$ \\
\hline Paulownia & 10 & - & - & $2 / 0.800$ & $2 / 0.613$ & - & $6 / 0.973$ \\
\hline The remaining 9 species & 34 & $0 / 0.001$ & $0 / 0$ & $8 / 1.82$ & $13 / 3.168$ & $6 / 1.678$ & $7 / 1.327$ \\
\hline Total & 2070 & $381 / 100$ & $255 / 100$ & $433 / 100$ & $307 / 100$ & $438 / 100$ & $256 / 100$ \\
\hline
\end{tabular}

Table 3. $t$-test results of the univariate distribution of the spatial-structure parameters.

\begin{tabular}{lll|ll|ll}
\hline \multirow{2}{*}{ Parameter } & \multicolumn{2}{c}{ Young } & \multicolumn{2}{c|}{ Middle-aged } & \multicolumn{2}{c}{ Near-mature } \\
\cline { 2 - 7 } & Control & Managed & Control & Managed & Control & Managed \\
\hline Mingling & $0.073 \pm 0.074$ & $0.176 \pm 0.113^{*}$ & $0.151 \pm 0.151$ & $0.347 \pm 0.196^{* *}$ & $0.171 \pm 0.142$ & $0.414 \pm 0.220^{* *}$ \\
Dominance & $0.481 \pm 0.016$ & $0.520 \pm 0.015^{* *}$ & $0.490 \pm 0.017$ & $0.486 \pm 0.017$ & $0.500 \pm 0.016$ & $0.488 \pm 0.024$ \\
Uniform-angle index & $0.552 \pm 0.018$ & $0.523 \pm 0.040$ & $0.545 \pm 0.017$ & $0.491 \pm 0.023^{* * *}$ & $0.518 \pm 0.056$ & $0.504 \pm 0.039$ \\
\hline
\end{tabular}

* significant at $P<0.05$. ** significant at $P<0.01$. $^{* * *}$ significant at $P<0.001$.

\subsubsection{Dominance $(U)$-uniform-angle index $(W)$ distribution}

No change for $U$ was observed with the increase of $U$ classes at each row of $W$, but the frequency of tress initially increased, reached a maximum at $W=0.50$, and then decreased with the increase of $W$ classes at each column of $U$. The frequency of trees with a random distribution increased in young and middle-aged stands but slightly decreased in near-mature stands when comparing managed treatments to the control, which showed values of 0.667 vs. $0.561,0.560$ vs. 0.545 , and 0.527 vs. 0.575 for young and middle-aged stands, respectively. However, the frequency of trees with a low degree of dominance $(U=0.00,0.25)$ and random distribution ( $W=0.50)$ showed no distinct difference between managed treatments and the control for all tree ages (Fig. 5).

\section{Discussion}

Close-to-nature management significantly improved the mingling of Masson pine forest and improved the proportion of trees with a high degree of mixing $(M=0.75,1.00)$ in the middle-aged and near-mature forests from the univariate distribution of structural parameters (Table 3 and Fig. 2). Overall, the stand was still in a low-middle mixed state after 

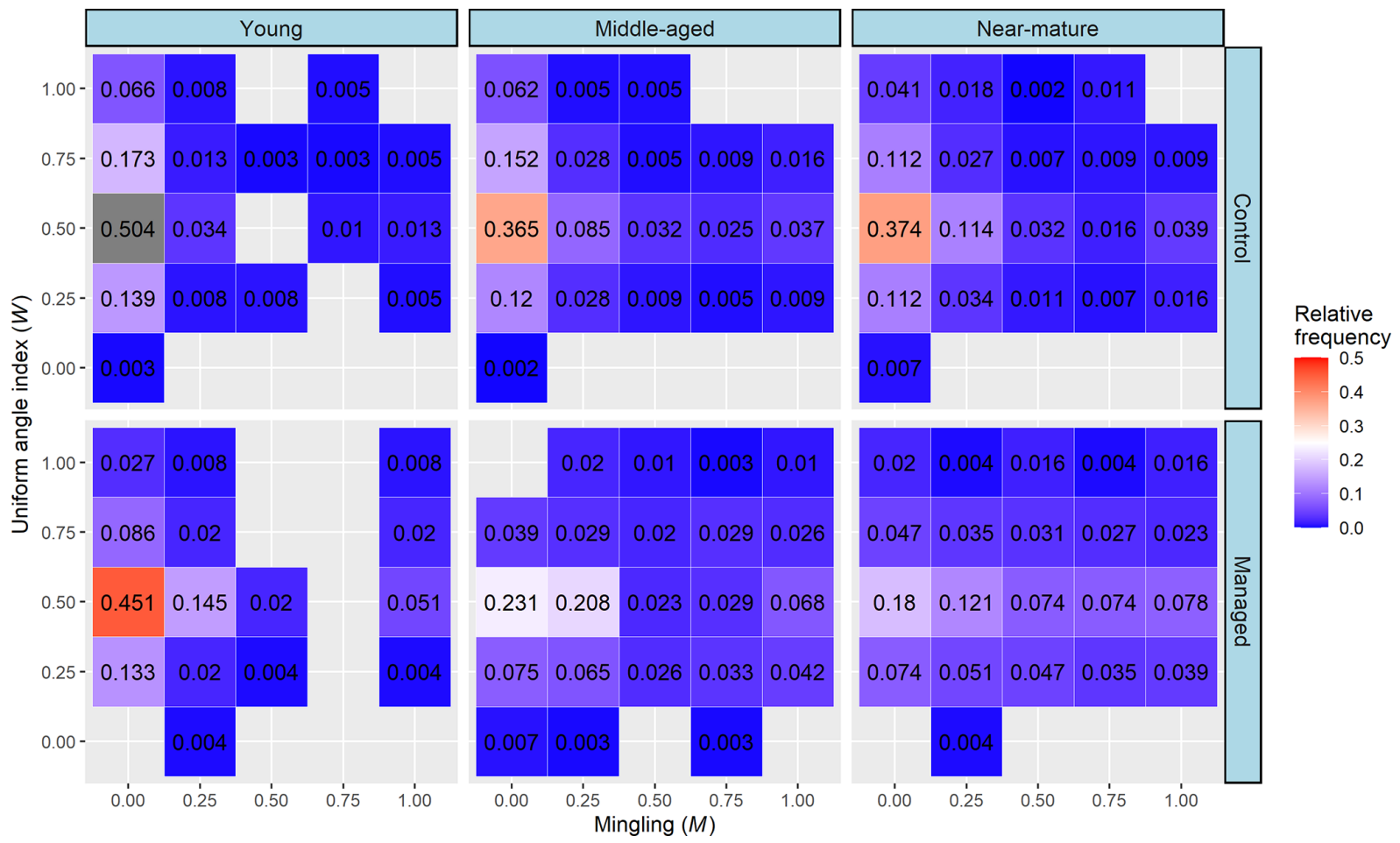

Figure 4. Bivariate distribution of $M$ and $W$ at different tree ages.
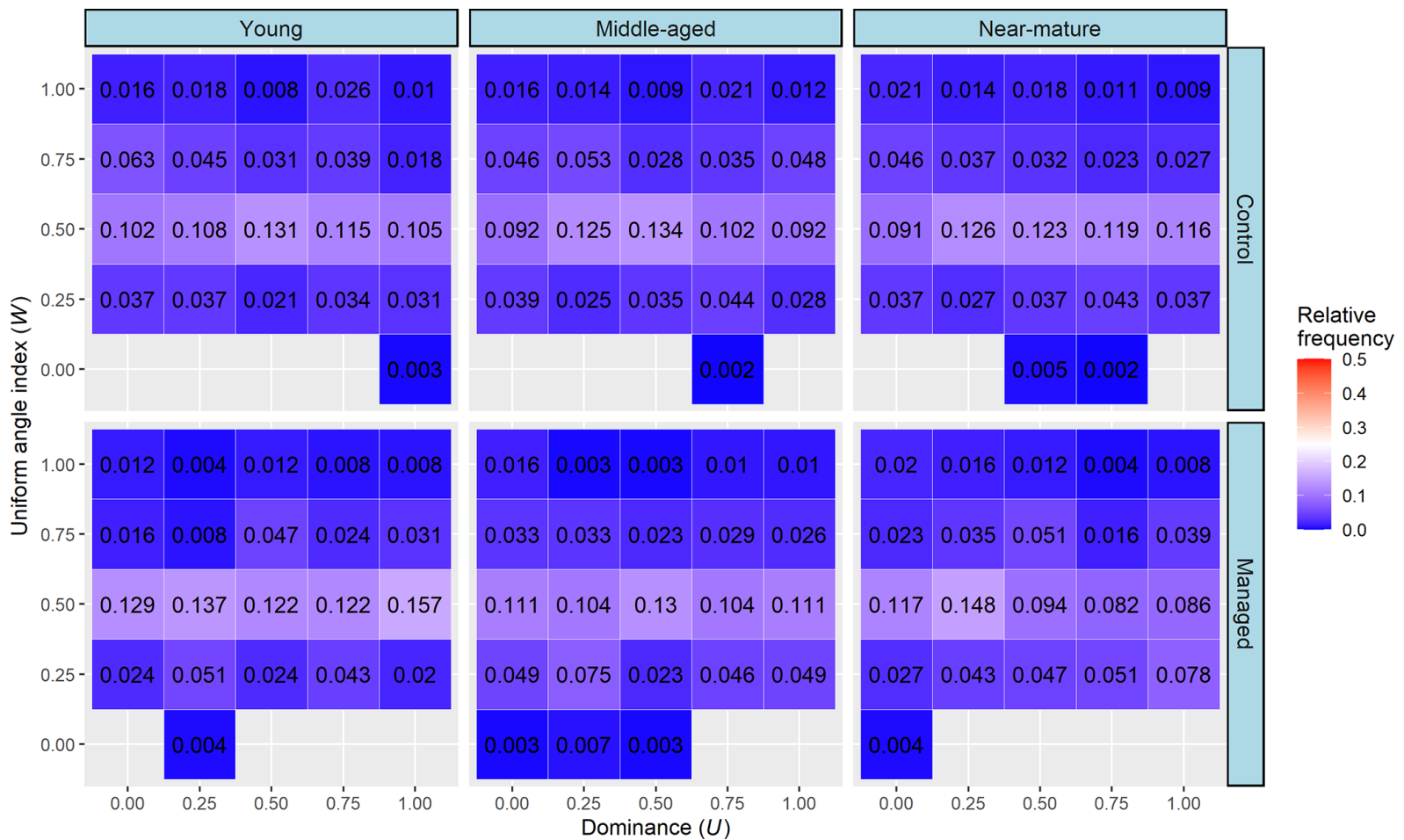

Figure 5. Bivariate distribution of $U$ and $W$ at different tree ages. 
CTNM, since a high degree of mixing means a high diversity of tree species (Pommerening and Uria-Diez, 2017; Wan et al., 2019). The relatively low average $M$ values $(M<0.50)$ indicate that the diversity of tree species of Masson pine forest is suboptimal, so further CTNM implemented at all stages of Masson pine forest is required. During the process of further CTNM, the target trees with mingling of 0 and 0.25 can be taken as the main adjustment factors; conditions conducive to the initiation and growth of heterogeneous species are created by reducing the number of trees of the same species around the target trees; and the diversity of species is, thus, increased. As we have seen, many new tree species appeared in managed Masson pine forest, especially at the middle and near-mature stages (Table 1). The implementation of CTNM significantly improved the average $U$ in young forest and subtly decreased the average $U$ in middle and near-mature forest. According to the definition of $U$, the smaller the value of $U$, the fewer the neighboring trees that are larger than the reference tree (Aguirre et al., 2003; Wan et al., 2019). This result suggests that CTNM in young forests contributes to neighboring tree growth, while CTNM in middle and near-mature forests assists reference tree (target tree) growth to a lesser extent. This is mainly because stands' size structures in managed forests are formed under the influence of the applied cutting method and thinning, which enables the subtle adjustment of microenvironmental conditions (Cogliastro and Paquette, 2012). Moreover, this study showed that CTNM did not significantly affect the $W$ of young forest but decreased the $W$ value to the bounds [0.475-0.517] and increased the relative frequency of trees with a random distribution in middle and near-mature forest. Results obtained show that young Masson pine forest still has a clustered distribution, while middle and near-mature Masson pine forests have changed from a cluster to a random distribution since the implementation of CTNM. Previous studies have demonstrated that the natural forest develops from aggregation to randomization, and the climax forest presents a random pattern (Wan et al., 2019; Zhang et al., 2018a, b); thus, the horizontal distributions of middle and near-mature Masson pine forest have become more reasonable with the implementation of CTNM.

The bivariate distribution of spatial-structure parameters jointly describes the distribution of any two structural parameters and thus can provide more important information about the fine-scale spatial structure of a forest (Chai et al., 2017; Li et al., 2014a). Wan et al. (2019) explained that an ideal bivariate distribution of a forest has three kinds of microstructure: randomly distributed trees with a highly mixed state $(W=0.5$ and $M=1)$, dominant trees with a random distribution $(U=0.00,0.25$, and $W=0.50)$, and dominant trees with a highly mixed state $(U=0,0.25$, and $M=0.75$, 1). In this study, we found that the relative frequency of trees having a micro-structure of randomly distributed trees with a high degree of mixture and dominant trees with a high degree of mixture was improved after the implementation of CTNM on Masson pine forest at middle-aged and nearmature stages, but the proportion of trees showing a microstructure of dominant trees with a highly mixed state had no obvious improvement. Combining the results of univariate and bivariate distribution of the spatial-structure parameters, we considered that the effect of CTNM on the spatial structure of Masson pine forest was mainly achieved by changing the distribution pattern and mingling degree; thus, these two parameters are the main adjustment factors for further implementation of CTNM. In addition, the effect of CTNM on spatial structure was more remarkable in middle-aged and near-mature Masson pine forests compared with the young forest. We thus recommend that an extensive CTNM be conducted on middle-aged and near-mature Masson pine forests, with the aim of obtaining an ideal spatial structure.

\section{Conclusions}

Close-to-nature management effectively improved the stand spatial structure and quality of the studied Masson pine forests, but the present structure situation was still suboptimal, and for the stands with low mixture and poor size differentiation the CTNM needs to be sustained. The method of frequency distribution of stand structure parameters can provide more direct and useful information about the heterogeneity of spatial structure from the size, species, and distribution pattern of tree population and community. CTNM according to this method can speed up the transition to a more natural stand structure and improve the success of forest management.

Data availability. The data that support the findings of this study are available from Zongzheng Chai (chaizz@126.com), upon reasonable request.

Author contributions. XF and ZC performed the sample collection, analyzed the data, and wrote the manuscript. WT and XG reviewed the manuscript. All authors approved the final manuscript.

Competing interests. The authors declare that they have no conflict of interest.

Financial support. This research has been supported by the Science and Technology Project of Guizhou, China (grant nos. QKHPTRC[2018]5261 and QKHJC[2019]1076); the Natural Science Foundation of China (grant no. 32001314); and the Science and Technology Foundation of the Department of Education of Guizhou Province, China (grant no. [2017]140).

Review statement. This paper was edited by John M. Halley and reviewed by Valentino Govigli and one anonymous referee. 


\section{References}

Aguirre, O., Hui, G. Y., von Gadow, K., and Jiménez, J.: An analysis of spatial forest structure using neighbourhoodbased variables, Forest Ecol. Manag., 183, 137-145, https://doi.org/10.1016/S0378-1127(03)00102-6, 2003.

Chai, Z. Z. and Tan, W.: Impacts of close-to-nature management on the stand states of Masson pine forests, Ecosystem health and sustainability, 6, 1846461, https://doi.org/10.1080/20964129.2020.1846461, 2020.

Chai, Z. Z., Sun, C. L., Wang, D. X., Liu, W. Z., and Zhang, C. S.: Spatial structure and dynamics of predominant populations in a virgin old-growth oak forest in the Qinling Mountains, China, Scand. J. For. Res., 32, 19-29, https://doi.org/10.1080/02827581.2016.1183703, 2017.

Chen, F., Yuan, Y. J., Yu, S. L., and Zhang, T. W.: Influence of climate warming and resin collection on the growth of Masson pine (Pinus massoniana) in a subtropical forest, southern China, Trees, 29, 1423-1430, https://doi.org/10.1007/s00468015-1222-3, 2015.

Cogliastro, A. and Paquette, A.: Thinning effect on light regime and growth of underplanted red oak and black cherry in postagricultural forests of south-eastern Canada, New Forests, 43, 941-954, https://doi.org/10.1007/s11056-012-9329-5, 2012.

Du, M., Ding, G., and Cai, Q.: The Transcriptomic Responses of Pinus massoniana to Drought Stress, Forests, 9, 326, https://doi.org/10.3390/f9060326, 2018.

Ghalandarayeshi, S., Nord-Larsen, T., Johannsen, V. K., and Larsen, J. B.: Spatial patterns of tree species in Suserup Skov-a seminatural forest in Denmark, Forest Ecol. Manag., 406, 391-401, https://doi.org/10.1016/j.foreco.2017.10.020, 2017.

Guan, L. L. and Wen, D. Z.: More nitrogen partition in structural proteins and decreased photosynthetic nitrogen-use efficiency of Pinus massoniana under in situ polluted stress, J. Plant Res., 124, 663-673, https://doi.org/10.1007/s10265-011-0405-2, 2011.

Hui, G. Y. and Gadow, K. v.: Das Winkelmaß. Herleitung des optimalen Standardwinkels, Allg. Forst-u. J.-Ztg, 173, 173-177, 2002.

Hui, G. Y., Gadow, K. v., and Albert, M.: The neighbourhood pattern-a new structure parameter for describing distribution of forest tree position, Scientia Silvae Sinicae, 35, 37-42, 1999.

Hui, G. Y., Gadow, K. v., Hu, Y. B., and Chen, B. W.: Characterizing forest spatial distribution pattern with the mean value of uniform angle index, Acta Ecologica Sinica, 24, 1225-1229, 2004.

Hui, G. Y., Gadow, K. v., Hu, Y. B., and Chen, B. W.: Structurebased forest management, China Forestry Press, Beijing, CN, 2007

Hui, G. Y., Hu, Y. B., and Xu, H.: Relationship between tree spatial structure and diameter classes in natural Korean pine mixed forest in north-eastern China, Allg. Forst Jagdztg, 177, 199-205, 2006.

Hui, G. Y., Zhao, X. H., Zhao, Z. H., and von Gadow, K.: Evaluating Tree Species Spatial Diversity Based on Neighborhood Relationships, Forest Sci., 57, 292-300, 2011.

Hui, G. Y., Zhang, G. G., Zhao, Z. H., and Yang, A. M.: Methods of Forest Structure Research: a Review, Current Forestry Reports, 5, 142-154, https://doi.org/10.1007/s40725-019-00090-7, 2019.

Li, Y. F., Hui, G. Y., Yu, S. F., Luo, Y. H., Yao, X. Y., and Ye, S. M.: Nearest neighbour relationships in $\mathrm{Pi}-$ nus yunnanensis var. tenuifolia forests along the Nanpan River, China, Forest-Biogeosciences and Forestry, 10, 746-753, https://doi.org/10.3832/ifor2405-010, 2017.

Li, Y. F., Hui, G. Y., Zhao, Z. H., and Hu, Y. B.: The bivariate distribution characteristics of spatial structure in natural Korean pine broad-leaved forest, J. Veg. Sci., 23, 1180-1190, https://doi.org/10.1111/j.1654-1103.2012.01431.x, 2012.

Li, Y. F., Hui, G. Y., Zhao, Z. H., Hu, Y. B., and Ye, S. M.: Spatial structural characteristics of three hardwood species in Korean pine broad-leaved forest-Validating the bivariate distribution of structural parameters from the point of tree population, Forest Ecol. Manag., 314, 17-25, https://doi.org/10.1016/j.foreco.2013.11.012, 2014a.

Li, Y. F., Ye, S. M., Hui, G. Y., Hu, Y. B., and Zhao, Z. H.: Spatial structure of timber harvested according to structurebased forest management, Forest Ecol. Manag., 322, 106-116, https://doi.org/10.1016/j.foreco.2014.02.042, 2014b.

Maleki, S. S., Mohammadi, K., and Ji, K. S.: Study on factors influencing transformation efficiency in Pinus massoniana using Agrobacterium tumefaciens, Plant Cell Tiss Org., 133, 437-445, https://doi.org/10.1007/s11240-018-1388-7, 2018.

O'Hara, K. L.: What is close-to-nature silviculture in a changing world?, Forestry, 89, 1-6, https://doi.org/10.1093/forestry/cpv043, 2016.

Pommerening, A. and Uria-Diez, J.: Do large forest trees tend towards high species mingling?, Ecol. Inform., 42, 139-147, https://doi.org/10.1016/j.ecoinf.2017.10.009, 2017.

Sackov, I., Sedliak, M., Kulla, L., and Bucha, T.: Inventory of Closeto-Nature Forests Based on the Combination of Airborne LiDAR Data and Aerial Multispectral Images Using a Single-Tree Approach, Forests, 8, 467, https://doi.org/10.3390/f8120467, 2017.

Gadow, K. v. and Füldner, K.: Zur bestandesbeschreibung in der forsteinrichtung, Forst und Holz, 48, 602-606, 1993.

Gadow, K. v., Hui, G. Y., and Albert, M.: Das Winkelmaß-Ein Strukturparameter zur Beschreibung der Individualverteilung in Waldbeständen, Centralblatt für das gesamte Forstwesen, 115, $1-10,1998$.

Wan, P., Zhang, G. Q., Zhao, Z. H., Hu, Y. B., Liu, W. Z., and Hui, G. Y.: Short-Term Effects of Different Forest Management Methods on Soil Microbial Communities of a Natural Quercus aliena var. acuteserrata Forest in Xiaolongshan, China, Forests, 10, 161, https://doi.org/10.3390/f10020161, 2019.

Wang, X. M., Lu, Y. C., Xing, H. T., Zeng, J., Xie, Y. S., Cai, D. X., Liu, X. Z., and Zhang, X. Q.: Effects of Close-toNature Conversion on Pinus massoniana Plantations at Different Stand Developmental Stages, Trop. Conserv. Sci., 11, 1-16, https://doi.org/10.1177/1940082918767953, 2018.

Wu, Y., Qin, K. L., Zhang, J. F., and Li, F. R.: Impacts of Close-tonature Management Technology on the Korean Pine Soil Chemical Properties in Northeast China, J. Forest Environ. Sci., 29, 300-306, 2013.

Zhang, G. Q., Hui, G. Y., Zhao, Z. H., Hu, Y. B., Wang, H. X., Liu, W. Z., and Zang, R. G.: Composition of basal area in natural forests based on the uniform angle index, Ecol. Inform., 45, 1-8, https://doi.org/10.1016/j.ecoinf.2018.01.002, 2018a.

Zhang, L. J., Hui, G. Y., Hu, Y. B., and Zhao, Z. H.: Spatial structural characteristics of forests dominated by Pinus tabulaeformis Carr, Plos One, 13, e0194710, https://doi.org/10.1371/journal.pone.0194710, 2018 b. 
Zhang, Y., Zhang, D. J., Li, X., and Zhang, J.: Contribution of soil fauna to the degradation of recalcitrant components in Cinnamomum camphora foliar litter in different-sized gaps in Pinus massoniana plantations, J. For. Res., 30, 931-941, 2019.

Zhao, Z. H., Hui, G. Y., Hu, Y. B., Wang, H. X., Zhang, G. Q., and von Gadow, K.: Testing the significance of different tree spatial distribution patterns based on the uniform angle index, Can. J. For. Res., 44, 1419-1425, https://doi.org/10.1139/cjfr-20140192, 2014 